\title{
Introduction of Materials Modelling into Processing Simulation
}

\section{Zhanli Guo ${ }^{1, a}$, Richard Turner ${ }^{2, b}$, Alisson D. Da Silva ${ }^{3, c}$, Nigel Sauders ${ }^{1, d}$, Florian Schroeder ${ }^{2, e}$, Paulo R. Cetlin ${ }^{3, f}$, and Jean-Philippe Schillé (1,g $^{2}$}

\author{
${ }^{1}$ Sente Software Ltd., Surrey Technology Centre, Guildford, GU2 7YG, U.K. \\ ${ }^{2}$ Department of Metallurgy and Materials, University of Birmingham, Birmingham, B15 2TT, U.K. \\ ${ }^{3}$ School of Engineering, Federal University of Minas Gerais, Belo Horizonte, Minas Gerais, 31270- \\ 901, Brazil. \\ az.guo@sentesoftware.co.uk, ${ }^{b}$ r.p.turner@bham.ac.uk, ${ }^{c}$ lissonds@gmail.com,
dnigel.saunders@thermotech.co.uk, ${ }^{e} \mathrm{FXS925@bham.ac.uk,}{ }^{\mathrm{f}}$ pcetlin@gmail.com,
9jp.schille@sentesoftware.co.uk
}

Keywords: materials modelling, CAE simulation, metals processing, flow stress curve, JMatPro.

\begin{abstract}
The introduction of materials modelling into computer-aided engineering (CAE) processing simulation has become popular in recent years, whereas the fundamental challenge lies in the development of material models that can calculate the properties essential for processing design and simulation. This paper reviews the recent development of such models and the material data that can be calculated include physical, thermophysical, and mechanical properties, as well as phase transformation kinetics. The calculated material data has been used as input to numerous CAE packages for the simulation of casting, welding, forming and heat treatments. Two case studies are presented here, one on the simulation of residual stress in linear friction welding of titanium alloys, and the other on the prediction of distortion and residual stress in heat-treated large steel rings.
\end{abstract}

\section{Introduction}

Computer-aided engineering (CAE) simulation tools are increasingly being used in metals industry to speed up processing and manufacturing. However, the current simulation practice has left the materials design outside the optimisation loop of product design and manufacturing, which reduces the potential design space and may result in suboptimal end products. The ultimate solution to this problem is to merge the materials design loop and the processing optimisation loop into one complete design space, i.e. to introduce materials modelling into processing simulation.

The fundamental technical challenge here is the development of material models to calculate the properties that are essential for processing design and simulation, which has been the focus of our research in the past two decades [1,2]. The properties that can now be calculated are wide ranging, which include: 1) temperature dependent physical and thermophysical properties, e.g. coefficient of thermal expansion and thermal conductivity, 2) temperature and strain rate dependent mechanical properties, e.g. strength and flow stress curves, and 3) phase transformation kinetics, e.g. TTT/CCT diagrams. These models are physical in nature and can provide the properties of each phase when necessary.

The material models have been implemented into JMatPro ${ }^{\circledR}[1]$, a computer software which calculates a wide range of materials properties for multi-component alloys, so that the calculated material data can be organised in a format that can be easily read as input by numerous commercial $\mathrm{CAE}$ tools for processing simulation. The first applications of this kind are found in casting simulations, where the calculated property data has been fed into packages such as MAGMASOFT $[3,4]$, PROCAST [5], and ABAQUS [6] to perform the simulation of heat transfer, fluid flow and/or stress distribution in various metallic systems e.g. Fe- [3], Ni- [3,5], Al- [4], and Mg- [6] based alloys. With the recent development of material models on the calculation of flow stress curves $[1,2]$, such applications have been extended to the simulation of welding $[7,8,9,10,11]$, hot forming $[12,13,14]$ and heat treatments $[15,16,17]$. This paper firstly reviews the important physical 
phenomena involved in metals processing and their governing laws. The material data essential for processing simulation are introduced, followed by the core material models. The success of coupling JMatPro with commercial CAE packages has been demonstrated via two case studies, one with FORGE on the simulation of residual stress in linear friction welding of titanium alloys, and the other with DEFORM on the prediction of distortion and residual stress in large steel rings during heat treatments.

\section{Materials Models Essential for Processing Simulation}

Physical Phenomena in Metal Processing. The physical phenomena involved in metal processing are quite complex as it is a dynamic process with confluent evolution of thermal field, stress/strain field and microstructure, and the physical laws behind are heat transfer, deformation mechanics and phase transformation kinetics. The interactions and interdependencies of the these phenomena are shown in Fig. 1. Consequently, an accurate coupling of these phenomena is essential to achieve reliable simulation.

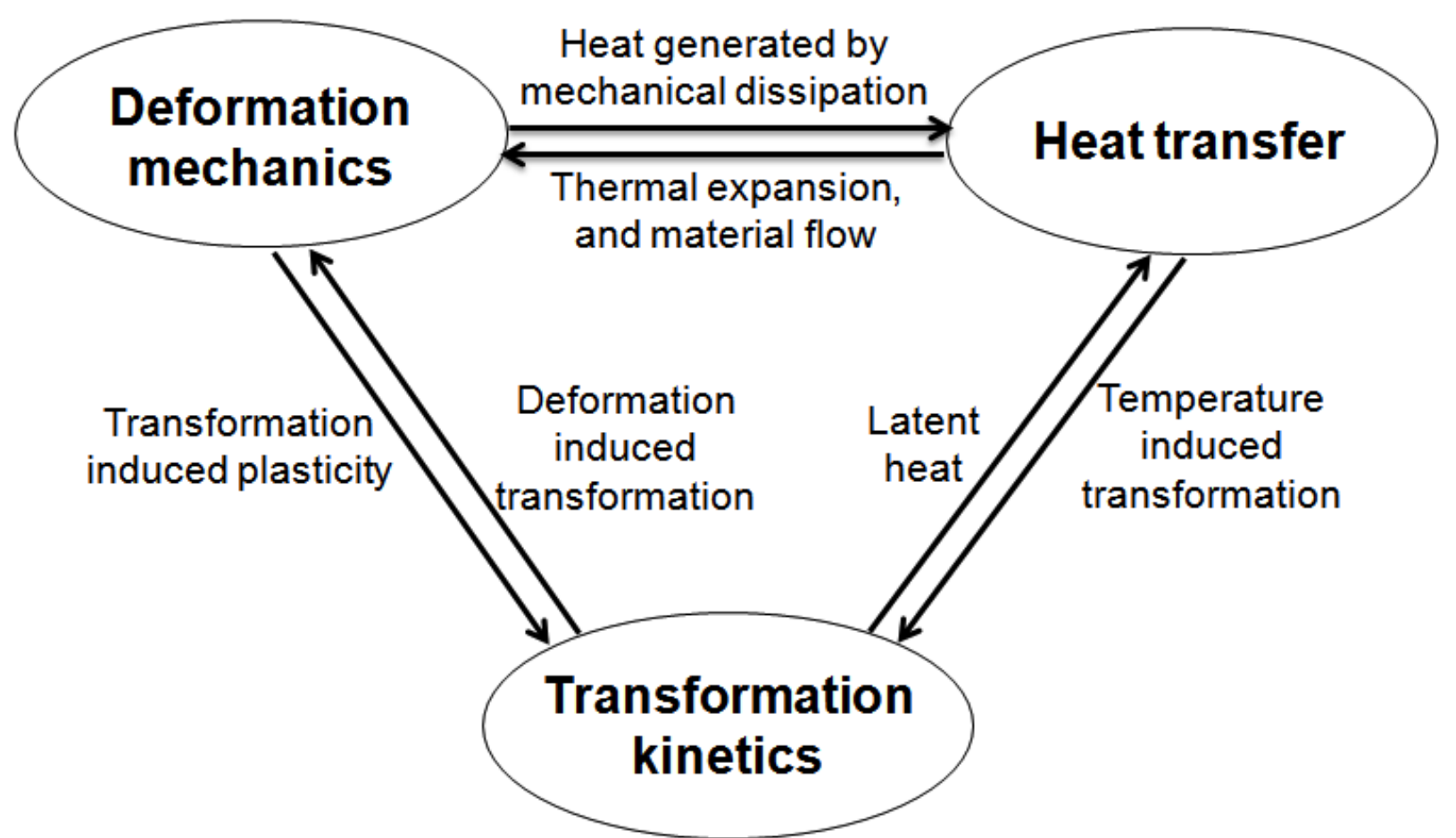

Fig. 1 Interactions between the three main physical phenomena in materials processing.

Heat transfer. The mathematical treatment of heat transfer is fairly mature and the governing equation is [18]:

$$
\rho c \dot{T}=\frac{\partial}{\partial x_{i}}\left(k \frac{\partial T}{\partial x_{i}}\right)+\sigma_{i j} \dot{\varepsilon}_{i j}^{p}+\sum L_{I J} \dot{\xi}_{I J}+\dot{Q}
$$

where $\rho, c, k$ and $L_{I J}$ are density, specific heat, thermal conductivity and latent heat from phase $I$ to phase $J$, produced by the progressive $J^{\text {th }}$ constituent with volume fraction $\zeta_{I J}$, respectively. $Q$ is the heat generated by external heat sources. $\dot{\xi}_{I J}$ is the time differentiation of $\zeta_{I J}$ and is termed the transformation rate. The $1^{\text {st }}$ term on the right hand side is from Fourier's law of heat conduction. The $2^{\text {nd }}, 3^{\text {rd }}$, and $4^{\text {th }}$ terms represent the heat due to plastic deformation, the heat absorbed or released during phase transformation, and other heat sources. 
Deformation mechanics. The mathematical treatment of deformation mechanics has been evolving, notably in the recent consideration of transformation-related effects. The calculation of total strain generated during processing can be decomposed into various individual strain contributions as follows [19]:

$$
\dot{\varepsilon}=\dot{\varepsilon}^{e}+\dot{\varepsilon}^{p}+\dot{\varepsilon}^{\theta}+\dot{\varepsilon}^{t r}+\dot{\varepsilon}^{p}
$$

where $\varepsilon^{e}, \varepsilon^{p}, \varepsilon^{\theta}, \varepsilon^{t r}$, and $\varepsilon^{t p}$ are the elastic, plastic, thermal, phase transformation, and transformation plasticity strain contributions, respectively. It has been recognised that when metal processing takes place in a temperature range where phase transformation takes place, the inclusions of $\varepsilon^{t r}$ and $\varepsilon^{t p}$ in Eq. 2 are essential for reliable simulation and their calculation can be referred to in Ref. 14.

Material Models. Although the importance of considering microstructural evolution in processing simulation has long been recognised, most of the CAE tools do not have built-in models for phase transformations, but rather relying on external user inputs typically in the form of TTT or CCT diagrams. This is primarily because there is yet one universal kinetic model that can deal with all the transformations in all alloy types, despite the tremendous effort spent on this subject by materials scientists. The fact that software developers in earlier days used to be of either mathematical or mechanical background does not help either. At present, two types of models are employed in JMatPro to deal with the various phase transformations involved in steels and other metallic systems.

Phase transformation model I - Kirkaldy model. Significant work has been undertaken to develop models that can calculate TTT and CCT diagrams for steels. The present model for the austenite decomposition to ferrite, pearlite and bainite is based on a previous model proposed by Kirkaldy et al., and it takes on the following form, which calculates the time $(\tau)$ to transform $x$ fraction of austenite at a temperature $T[20]$,

$$
\tau(x, T)=\frac{1}{\alpha D \Delta T^{q}} \int_{0}^{x} \frac{d x}{x^{2(1-x) / 3}(1-x)^{2 x / 3}}
$$

where $\alpha=\beta 2^{(G-1) / 2}, \beta$ is an empirical coefficient, $G$ is the ASTM grain size, $D$ is an effective diffusion coefficient, $\Delta T$ is the undercooling, and $q$ is an exponent dependent on the diffusion mechanism. Once the TTT diagram is calculated, the CCT diagram can be obtained using wellestablished additivity rules [20]. Such calculation can be performed with good accuracy for steels over a wide composition, including medium to high alloy types, tool steels and stainless steels [21].

Phase transformation model II - Johnson-Mehl-Avrami-Kolmogorov model. This type of model has been employed to studied transformations such as the precipitation of secondary phases in stainless steels [22], the formation of gamma prime in a gamma matrix in Ni-based superalloys $[23,24]$, as well as the formation of alpha phase from a beta matrix in titanium alloys [25]. The model allows the morphology of the precipitate to be considered as well as specifics associated with potential nucleant sites. For the case of steady state nucleation, the governing equation can be written as [22]:

$$
X=\frac{V_{f}}{V_{e q}(T)}=1-\exp \left(-f N_{r} G_{r}^{3} t^{4}\right)
$$

where $X$ is the volume fraction of the product phase, $V_{f}$ is the volume transformed, $V_{e q}(T)$ is the equilibrium volume amount of the phase at temperature $T, f$ is a shape factor, $N_{r}$ is the nucleation rate, $G_{r}$ is the growth rate and $t$ is time. For the case where site saturation occurs, one has [22]:

$$
X=1-\exp \left(-f N_{o} G_{r}^{3} t^{3}\right)
$$


where $N_{o}$ is the total number of active nucleant sites. The method for calculating $N_{r}$ and $G_{r}$ has been described in Ref. 22.

Microstructure-Property Relationships. Whether microstructure-property relationship should be called material models remains debatable. It is nonetheless listed separately here to highlight its importance, as this is where various structural length scales (dislocations, particles, grains, etc.) are naturally covered, therefore playing a critical role in successful realisation of multiscale modelling [26]. Simulation of heat transfer requires the knowledge of thermal conductivity and heat capacity, and deformation simulation requires elastic modulus, Poisson's ratio, thermal expansion coefficient, strength and flow stress curves. Now that phase transformation kinetics gives microstructure at certain processing treatments, microstructure-property models are needed to calculate the required material properties, all of which are a function of temperature and/or strain rate.

For each individual phase in a multi-component system, properties, such as molar volume, thermal conductivity, Young's modulus, and Poisson's ratio, are calculated using simple pair-wise mixture models [27]:

$$
P=\sum_{i} x_{i} P_{i}^{o}+\sum_{i} \sum_{j>i} x_{i} x_{j} \sum_{v} \Omega_{i j}^{v}\left(x_{i}-x_{j}\right)^{v}
$$

where $P$ is the property of the phase, $P_{i}^{0}$ is the property of the phase in the pure element, $\Omega_{i j}{ }^{j}$ is a binary interaction parameter dependent on the value of $v, x_{i}$ and $x_{j}$ are the mole fractions of elements $i$ and $j$ in the phase. Both $P_{i}{ }^{0}$ and $\Omega_{i j}{ }^{\nu}$ are temperature dependent and it is possible to include ternary or higher order effects where appropriate.

Once the property of each individual phase is defined, finally, the property of the alloy can be calculated via appropriate mixture models [28,29]. Naturally such material properties can be provided for each phase when needed. JMatPro's ability to calculate physical and thermophysical properties has been well documented in previous work for various metallic systems [30], and thermal conductivity, heat capacity, Young's modulus, Poisson's ratio, and thermal expansion coefficient can be modelled this way. The calculation of mechanical properties, i.e. strength and flow stress curve, requires models based on strengthening mechanisms. While the contribution of solid solution strengthening follows an approach similar to that of Eq. 8, the consideration of HallPatch grain size effect and precipitation strengthening have to be considered differently. Details of the strengthening models can be referred to in Refs. 22, 23, and 24 and the calculation of flow stress curve is provided in Ref. 31.

\section{Case Study 1: Simulation of Residual Stress in Linear Friction Welding}

Linear friction welding (LFW) is a solid-state joining technique. It involves the localised heating caused by the reciprocating action of two surfaces brought into contact at high frequency under an applied load, and offers distinct advantage of producing a consolidated joint whilst the material remains below its solidus temperature. Recent work has confirmed that significant residual stress is present after LFW processing [32,33], so it is of considerable interest to understand the origin and magnitude of the residual stress.

Numerical simulation of LFW applications has been studied in recent years using a variety of CAE packages $[11,34,35,36,37,38]$. As the heating produced by the shearing and deformation of the material is significant, the process must be modelled as a fully coupled thermal-mechanical analysis. Most of the commercial packages can deal with such coupling but to obtain all the material data required to perform such analysis can be quite difficult. This is because the availability of such data in literature is often restricted to lower temperatures, and extrapolation methods have to be used to estimate high temperature properties, which can lead to significant uncertainties in the simulation results. 
With JMatPro, the problem of lacking material data has been largely solved, as demonstrated in recent work [11]. The material data calculated using JMatPro included a tabular flow-stress input deck for varying strains, strain rates and temperatures; and tables for thermal conductivity, thermal expansion, specific heat, density and Poisson's ratio, all as a function of temperature. Young's modulus and thermal conductivity of the Ti-6Al-4V alloy used in their study are plotted in Fig. 2 as example calculations. The calculated flow stress curves of this alloy are shown in Fig. 3, together with experimental data [39], corresponding to various strain rates at $950^{\circ} \mathrm{C}$ and various temperatures at a strain rate $0.1 \mathrm{~s}^{-1}$, respectively.
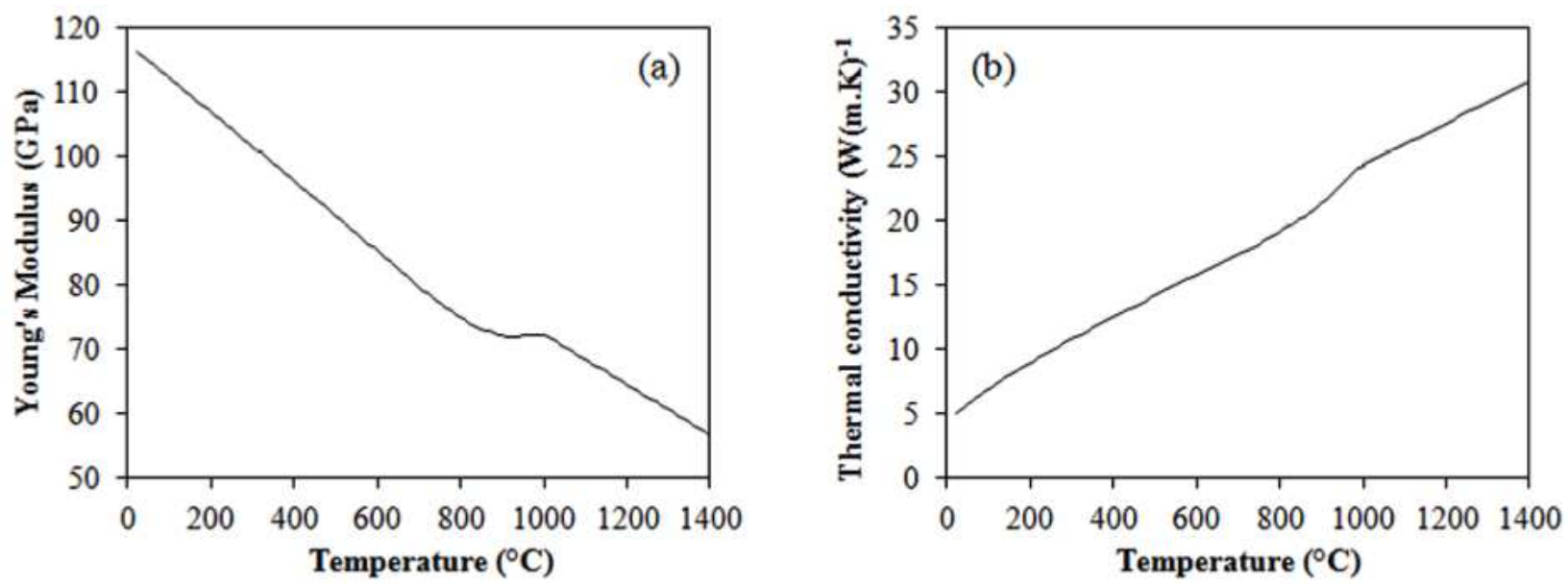

Fig. 2 The calculated Young modulus (a) and thermal conductivity (b) of alloy Ti-6Al-4V.
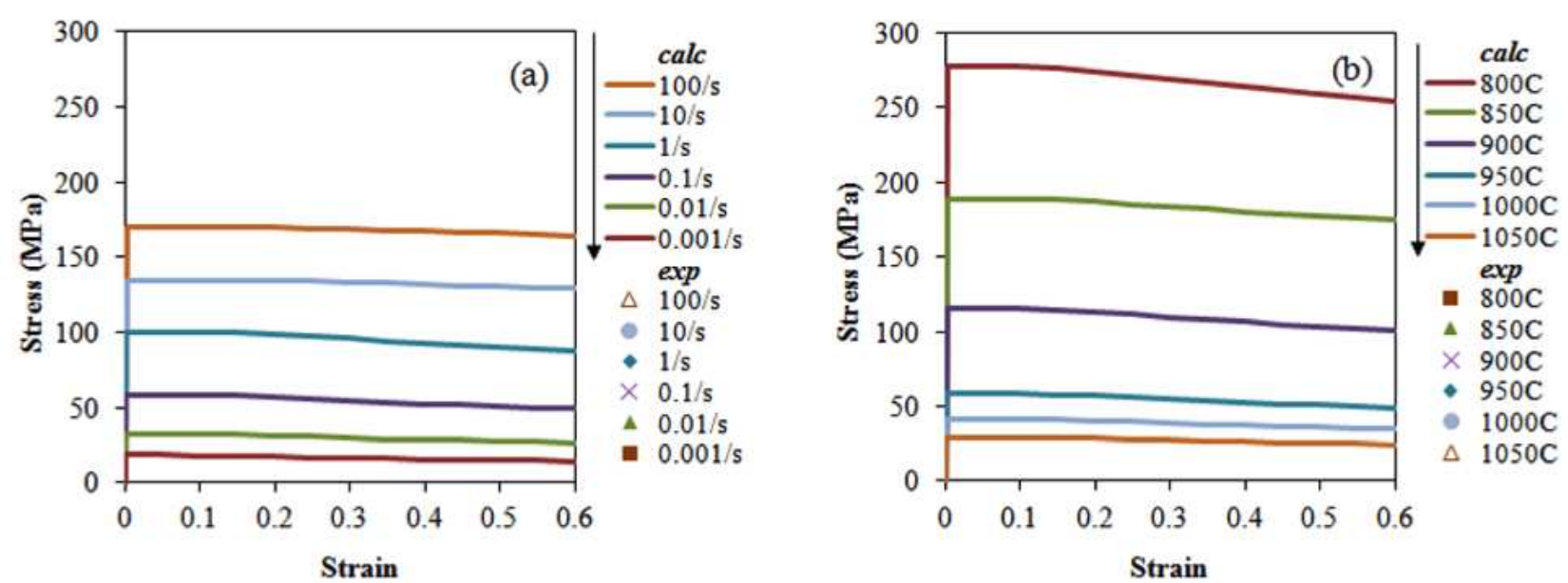

Fig. 3 Comparison between experimental and calculated flow stress curves for a Ti-6Al-4V (ELI) alloy at (a) $950^{\circ} \mathrm{C}$ with various strain rates, and (b) various temperatures with strain rate $0.1 / \mathrm{s}$.

Turner et al. [37] and Schroeder et al. [38] targeted flash morphology accuracy to provide a visual verification that their finite element (FE) models were considering the correct deformation modes and that material data was reasonable. Fig. 4 illustrates the predicted flash morphology within the models for (top) low amplitude, high pressure, and (bottom) high amplitude and low pressure, and compares the modelled predictions to similar experimental welds. The nature of the flash morphology between modelled prediction and experiment are very similar. The distinct rippling observed in the $2^{\text {nd }}$ case suggests that the flow-stress tabular input for Ti-6Al-4V used in these FE models has captured the correct flow and behaviour properties of this material, relating to the deformation mode of the flash as it is extruded from the weld line.

Turner et al. also described the residual stress formation mechanism within a linear friction weld in their work [37]. During the welding process, the rapid oscillating motion of the one component causes regions of high stress to be developed, however, as the material continues to heat, these stresses play a less-important role. The stresses that come to dominate the final residual 
stress state will be those produced during the cooling of the part, when a hot layer of material is slowly air cooled, whilst constrained by colder, stiff material. This produces a central band of material in tensile stress as illustrated in Fig. 4. Whilst residual stress formation is an important output to consider, to date this has only been explored through numerical methods once. Reasonable comparisons between experimentally measured [32,33] residual stress and the FE predictions were observed, these are presented in Fig. 5. The successful validation of residual stress predictions provides further evidence that the material database employed in the Forge models was a reasonable representation of the material behaviour at a variety of processing conditions.

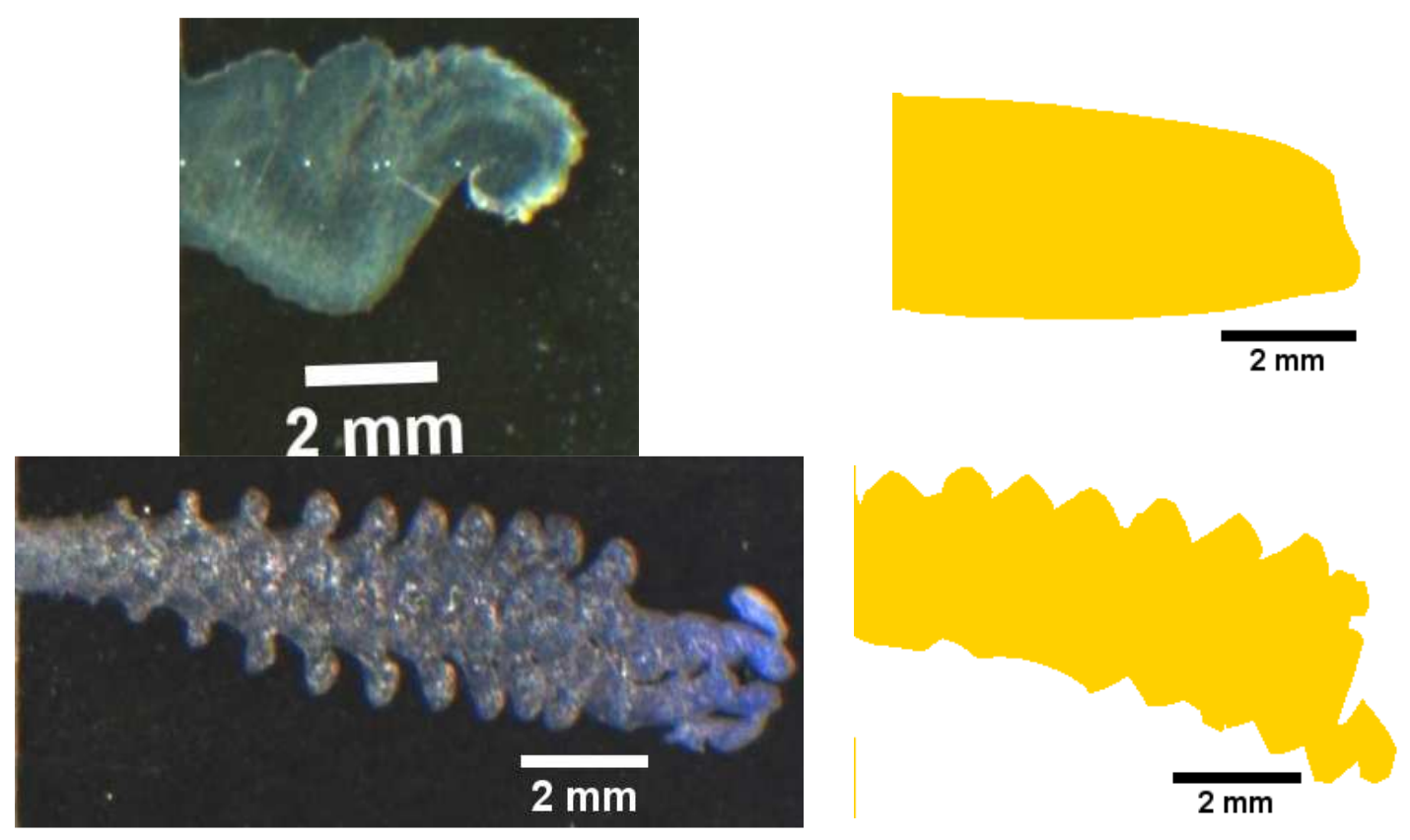

Fig. 4 Examples of flash formation during LFW; top: smaller amplitude and high applied load and associated modelling; bottom: large amplitude and lower applied load and associated modelling.
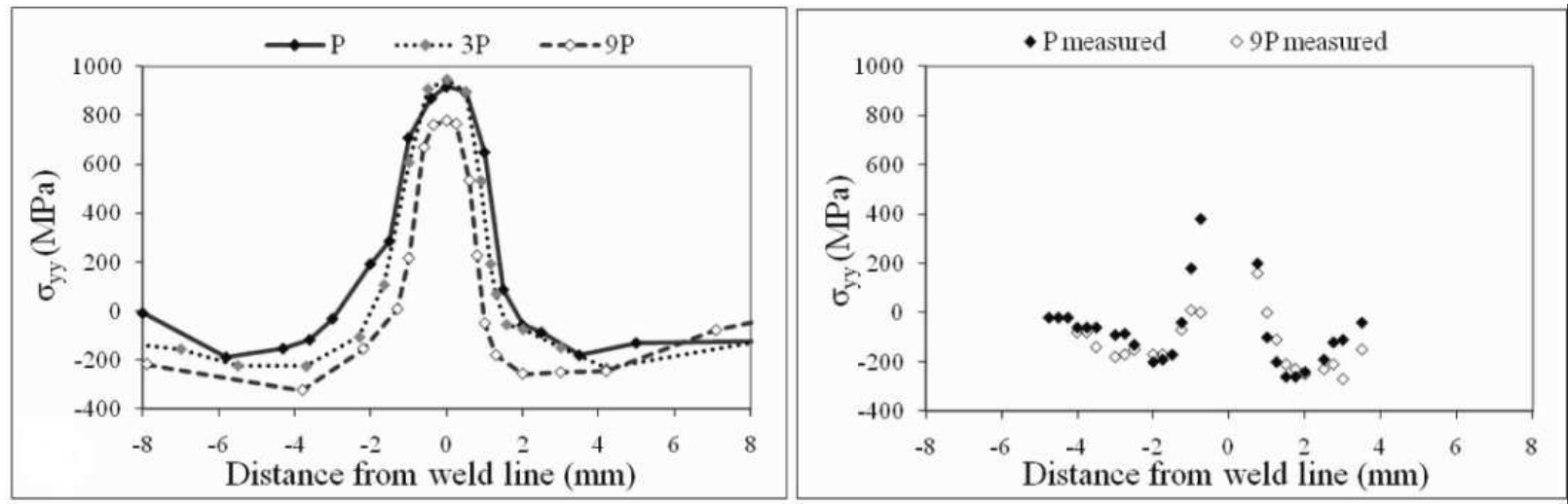

Fig. 5 A comparison of residual stress predictions (left) vs. measurements (right) for three Ti-6Al-4V welds at different pressures.

\section{Case Study 2: Prediction of Distortion and Residual Stresses in Heat-treated Large Rings}

Steel rings distort and develop undesired residual stresses during heat treatments, especially those with a large outer diameter to wall thickness ratio. Since distortion is unavoidable, the main focus is therefore to accurately account for the distortion during design and manufacturing. Any simulation involving heat treatment must be able to deal with heat transfer, phase transformation and material deformation in a coupled fashion. Two factors are critical in the accurate prediction of 
distortion and residual stresses of a ring during quenching simulations, i.e. accurate material properties, and heat transfer coefficient (as a function of time and location) between the quenchant and ring. While the material data can be calculated using the JMatPro software [40], the heat transfer coefficient data has to be provided elsewhere [41]. A pilot study had been carried out to test this methodology and has obtained simulation results in good agreement with experimental observations [16].

Heat treatments consist of heating and cooling and it is therefore important to know the materials properties in a complete thermal cycle. The initial microstructure of the material before heat treatment is not always known, in which case, the microstructure can be reasonably assumed to remain unchanged below its final heat treatment temperature, above which the phase amounts and constituents are allowed to change to their equilibrium values. The linear expansion of alloy 4140 used in this study during a thermal cycle is shown in Fig. 6 as an example, where both heating and cooling rates are set as $10^{\circ} \mathrm{C} / \mathrm{s}$.

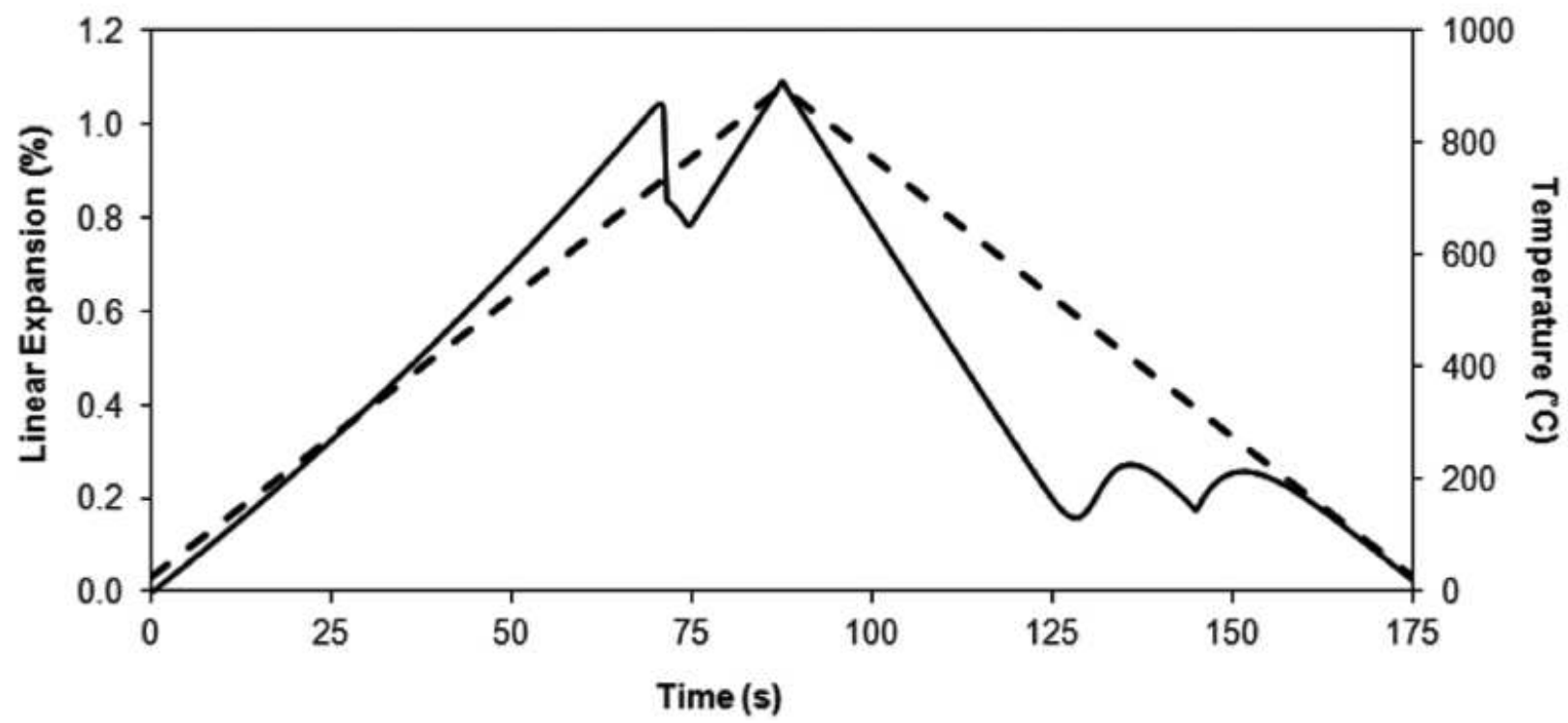

Fig. 6 Linear expansion of alloy 4140 during a heating and cooling cycle, both at $10^{\circ} \mathrm{C} / \mathrm{s}$.

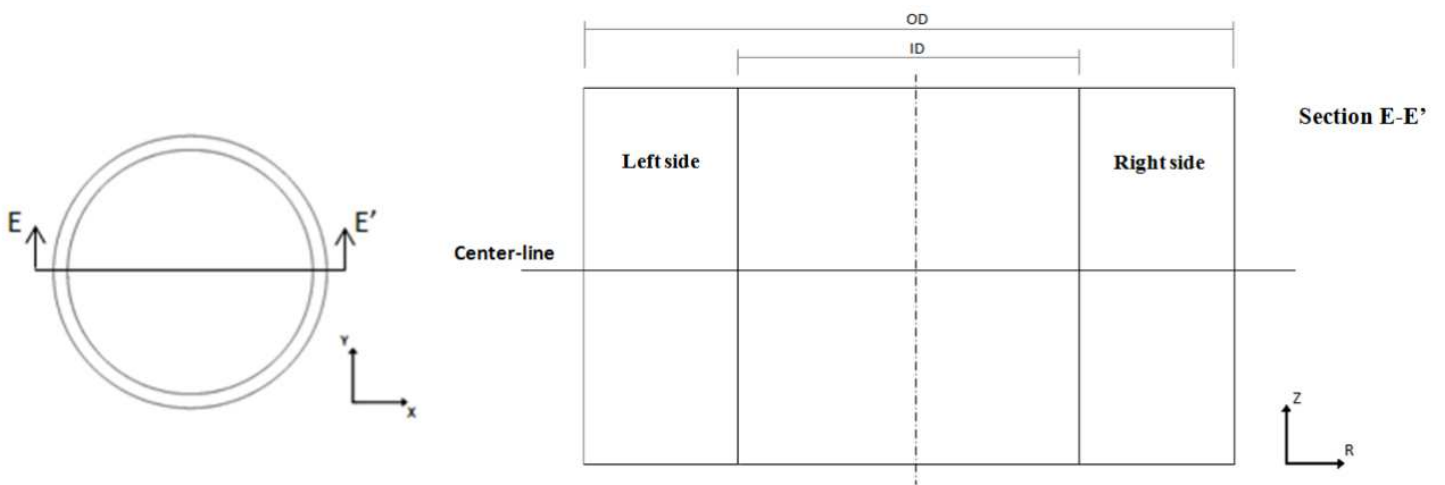

Fig. 7 Schematic of the ring cross section: the indicated center-line is used in later simulation.

The geometry of the ring is given in Fig. 7. The inner diameter (ID) and outer diameter (OD) are 1163.8 and $1296.9 \mathrm{~mm}$, respectively, with a thickness $163.5 \mathrm{~mm}$. A schematic drawing of its cross section is also given here for further analysis. Followed the hot rolling and normalising processes, the ring is hardened through quenching. Since no ovality is observed in the normalizing process, the quenching process was simulated considering a ring with no initial residual stresses. The ring was heated to $900^{\circ} \mathrm{C}$, expanding its geometry and increasing $14 \mathrm{~mm}$ in outer diameter. 
The heated ring is considered completely austenitised at $900^{\circ} \mathrm{C}$ before quenching simulation. For the fast cooling stage, the heat transfer coefficient was applied to the ring surface as a function of temperature and position on the surface, following the hypothetical configuration defined in Ref. 17. The maximum and minimum dimensions at the end of the quenching simulation were 1304.2 $\mathrm{mm}$ and $1291.4 \mathrm{~mm}$, respectively, i.e. an ovality of $12.8 \mathrm{~mm}$, as shown in Fig. 8. It should be noted that the blue (dark) geometry has its displacement magnified 10 times, and is superimposed on the reference geometry with no magnification. The distortion is a result of the non-homogeneous distribution of residual stress along the ring circumference, as clearly shown in Fig. 9.

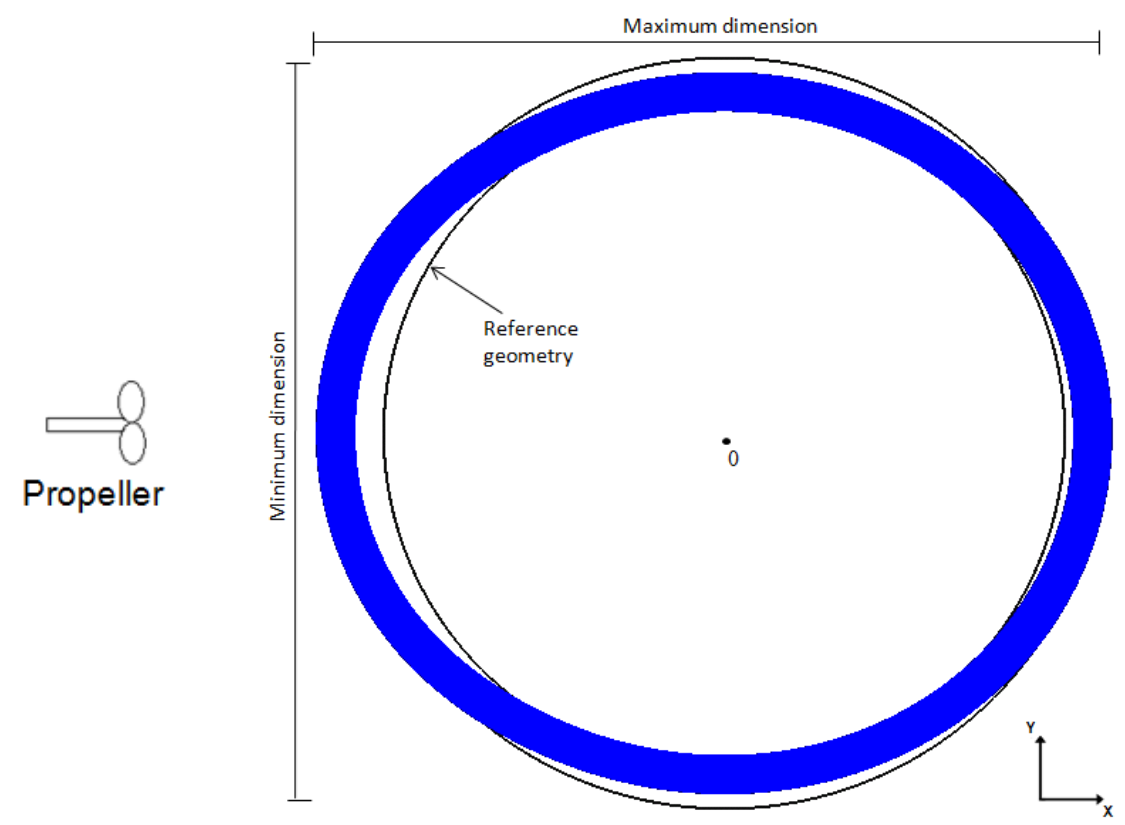

Fig. 8 Simulated distortion at the end of quenching (displacement magnified 10x). The position of the propeller used in cooling is also schematically shown here.
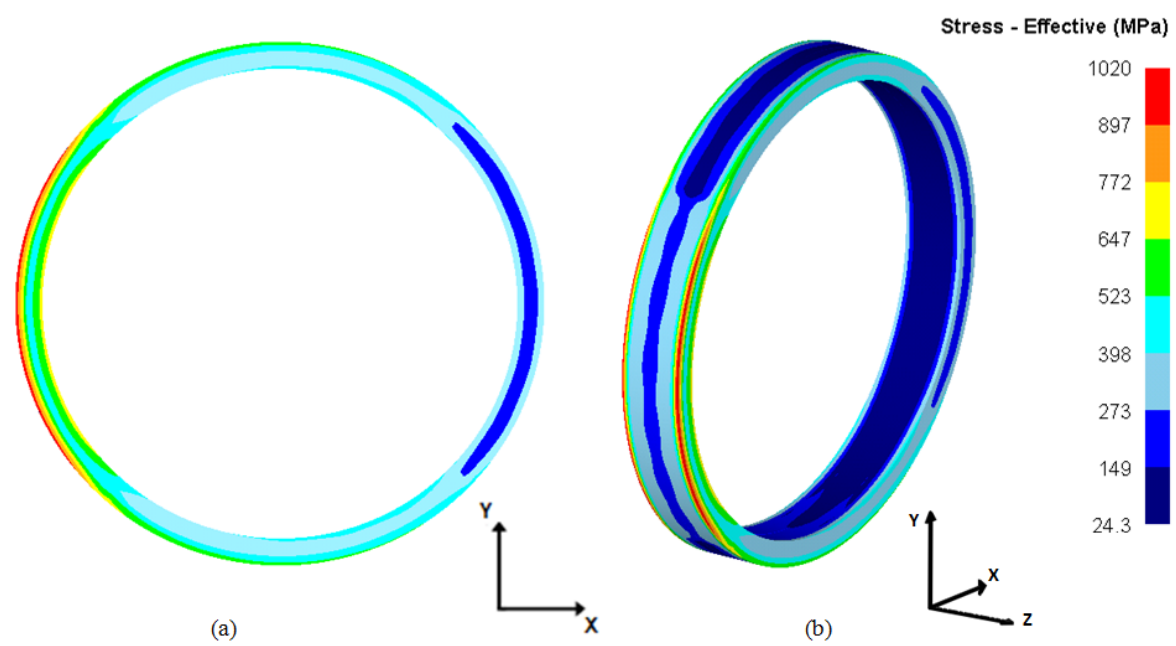

Fig. 9 Residual stress in the distorted ring after quenching simulation: (a) top and (b) 3D views. 


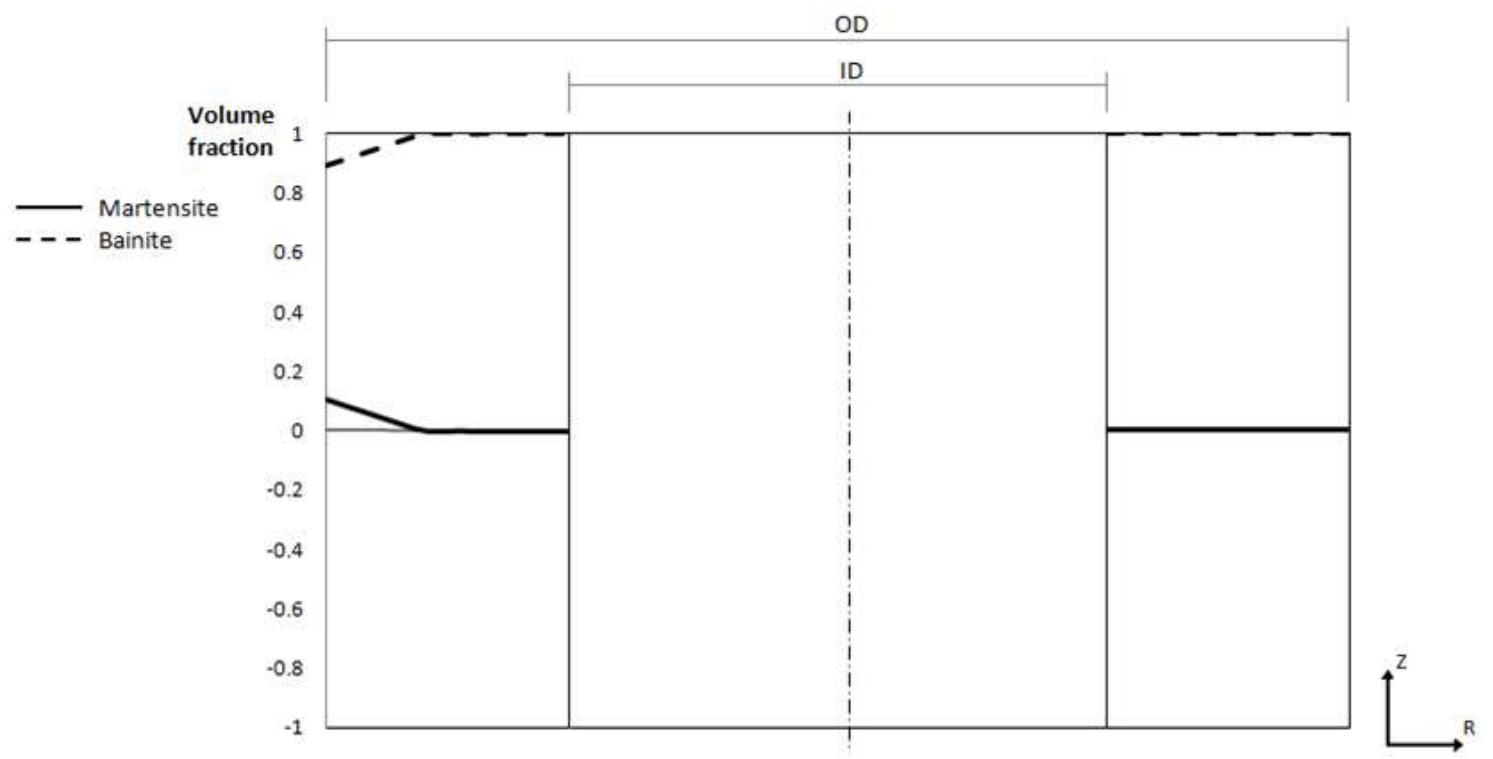

Fig. 10 Volume fraction of bainite and martensite on the center-line of the ring cross section.

To gain a deeper understanding of the formation of residual stress, one has to look at the microstructure evolution during quenching. The volume fraction of martensite and bainite along the centre-line (defined in Fig. 7) is shown in Fig. 10. The right side of the ring, i.e. on the far side of the propeller (slower cooling) achieves $100 \%$ bainite along the centre-line, where the left side, i.e. on the near side of the propeller (faster cooling) sees the formation of martensite in the region closer to the outside surface. The martensite formation expands this portion of the material, creating compressive stresses on the outside surface and tensile stresses on the inside surface, and consequently resulting in the ovality distortion shown in Fig. 8.

\section{Discussion}

Drawbacks of Equation-based Material Flow Laws. Among all the material data essential for processing simulation, a comprehensive set of rheological data is the most difficult one to obtain. Not only is it a function of temperature, strain and strain rate, but accurate simulation requires it to be available for each major (matrix) phase that may appear in the processing (temperature) window. The fact that most, if not all, metals such as Ni-, Ti-, Fe-, and Al-based alloys undergo a rapid degradation of mechanical properties at elevated temperatures [4] means any equation-based material flow stress law, such as the Johnson-Cook [34], or the Norton-Hoff [42], would struggle to accurately reflect the material's flow behaviour at both high-temperature and low-temperature regimes. The model for the calculation of flow stress curve inside JMatPro is based on deformation mechanisms. Therefore it naturally allows the switch of mechanisms to take place in response to the regime of temperature, strain and strain rate that it enters [31]. The model's prediction nature also means such data can be well populated to match the user's demand, reducing the uncertainty caused by employing interpolation methods inside CAE packages.

Property per Phase to Replace Property of the Alloy. Metals processing usually consists of heating and cooling procedures and the materials properties can be different between the two, as shown in Fig. 6 for steels. Different rates of cooling may lead to different transformation products, and in turn different properties, as demonstrated in Ref. 40 for steels and Ref. 25 for titanium alloys. The current processing simulation usually reads one set of physical and thermophysical data with temperature dependence, and does not distinguish cooling from heating. It remains to be seen whether the effect of such practice may be deemed as second order on simulation results. To remove the uncertainly caused by this, the ultimate solution would be to considere the evolution of microstructure at deeper levels inside the CAE solver, where the input data required becomes 
property per phase, instead of the property of the alloy. As JMatPro is already capable of producing property per phase when needed, it is now down to CAE software developers to decide how to improve their software.

\section{Summary}

The development of material models has reached a stage where many of the intrinsic property data essential for processing simulation can be calculated, which otherwise have to be gathered by means of time-consuming and costly experimental testing. The ability of JMatPro in providing such data has been gradually recognised by the CAE community, which prompts CAE packages such as MAGMASOFT and SIMUFACT to design a standard option of loading material data from JMatPro in their latest versions. It now becomes possible to have alloy design incorporated into the design optimisation loop of product/processing, moving closer to true virtual design, where the time-consuming physical prototyping is not necessary until sufficient confidence is accumulated.

\section{Acknowledgement}

ZG would like to thank Drs. G. Huang and H. Schafstall of Simufact Engineering GmbH for the useful discussions during the preparation of this manuscript.

\section{References}

[1] Information on http://www.sentesoftware.co.uk/downloads/articles-and-papers.aspx, Sente Software Ltd., U.K. 2012.

[2] Z. Guo, N. Saunders, A.P. Miodownik and J.P. Schillé: Mater. Sci. Eng. A Vol. 499 (2009), pp. 7-13.

[3] K.D. Carlson, S. Ou and C. Bechermann: Metall. Mater. Trans. B Vol. 36B (2005), pp. 843856.

[4] Z. Guo, N. Saunders, E. Hepp and J.P. Schillé, in: The $5^{\text {th }}$ Decennial International Conference on Solidification Processing, 23-25 July, 2007, Sheffield, U.K.

[5] X. Zhang X. Cao, H.L. Luo, D. Feng and S.P. Li: Israel J. Chemistry Vol. 47 (2008), pp. 363368.

[6] H. Hao, D.M. Maijer, M.A. Wells, S.L. Cockcroft, D. Sediako and S. Hibbins: Metall. Mater. Trans. A Vol. 35A (2004), pp. 3843-3854.

[7] A. Krasovskyy, S. Sönnichsen and D. Bachmann: Procedia Eng. Vol. 10 (2011), pp. 506-511.

[8] A. Krasovskyy and D. Bachmann: Int. J. Struct. Integr., Vol. 3, No. 4 (2012), pp. 326-343.

[9] V. Vivek, B. Santhosh Kumar and J.R. Nataraj: Intern. J. Engineering Res. Appl., Vol. 2, No. 5 (2012), pp. 1550-1556.

[10]A.A. Bhatti and Z. Barsoum: J. Strain Anal. Eng. Design, Vol. 47, No. 8 (2012), pp.539-552.

[11]R. Turner, R.M. Ward, R. March and R.C. Reed: Metall. Mater. Trans. B, Vol. 43B (2012), pp. 186-197.

[12]M.S. Chae, G.D. Lee, Y.S. Suh, K.H. Lee and Y.S. Kim: Trans. Mater. Process. Vol. 18, No. 3 (2009), pp. 236-244.

[13] O.S. Seo, S.J. Yoon, C.H. Suh and H.Y. Kim, in: AIP Conf. Proc. 1252, (Proceedings of the 10th International Conference on Numerical Methods in Industrial Forming Processes, Eds. F. Barlat, Y.H. Moon and M.G. Lee, 13-17 June 2010, Pohang, Korea), pp. 1216-1222.

[14]Z. Guo, G. Kang and N. Saunders, in: The 13th International Conference on Metal Forming, 19-22 September 2010, Toyohashi, Japan.

[15] J. Fu, Y.T. Li and H.P. Qi: Adv. Mater. Res. Vols. 317-319 (2011), pp.19-23.

[16] A.D. da Silva, T.A. Pedrosa, J.L. Gonzalez-Mendez, X. Jiang, P.R. Cetlin and T. Altan: Materials \& Design Vol. 42 (2012), pp.55-61. 
[17]A.D. da Silva, Z. Guo, J.P. Schillé, T. Altan and P.R. Cetlin, in: 32nd SENAFOR, 22-24 October, 2012, Porto Alegre, RS, Brazil.

[18] K. Arimoto, D. Lambert, G. Li, A. Arvind and W.T. Wu, in: Heat Treating 1998: Proceedings of the 18th Conference, ASM International, 1999, pp. 639-644.

[19] K. Arimoto, H. Kim, M. Narazaki, D. Lambert and W.T. Wu, in: Heat Treating - Including Quenching and Control of Distortion: An International Symposium in Honor of Professors Bozidar Liscic and Hans M. Tensi: Proceedings of the 21st Conference, ASM International, 2002, pp. 144-151.

[20] J.S. Kirkaldy and D. Venugopolan, in: Phase Transformations in Ferrous Alloys, eds. A.R. Marder and J.I. Goldstein, AIME, (Warrendale, PA: AIME, 1984) p. 125.

[21] N. Saunders, Z. Guo, X. Li, A.P. Miodownik and J.P. Schillé: The calculation of TTT and CCT diagrams for general steels, Internal report, Sente Software Ltd., U.K., 2004.

[22] X. Li, A.P. Miodownik and N. Saunders: Mater.Sci. Technol., Vol. 18 (2002), p. 861.

[23] N. Saunders, Z. Guo, X. Li, A.P. Miodownik and J.P. Schillé, in: Superalloys 2004, eds. K.A. Green et al (Warrendale, PA: TMS, 2004), 849.

[24] Z. Guo, N. Saunders, A.P. Miodownik and J.P. Schillé, Mater. Sci. Forum Vols. 546-549 (2007), p. 1319.

[25] Z. Guo, N. Saunders, A.P. Miodownik and J.P. Schillé, in: Ti-2011: The 12th World Conference on Titanium, 19-24 June 2011, Beijing, China

[26] M.F. Horstemeyer: Integrated Computational Materials Engineering for Metals - Using Multiscale Modeling to Invigorate Engineering Design with Science, (Wiley-TMS, 2012).

[27] X. Li, A.P. Miodownik and N. Saunders: J. Phase Equilibria, Vol.22 (2001) pp.247-253.

[28]Z. Fan, P. Tsakiropoulos, A.P. Miodownik, J. Mat. Sci. Vol. 29 (1994) p. 141.

[29]A.P. Miodownik, N. Saunders and J.P. Schillé, Sente Software Ltd., unpublished research.

[30]Z. Guo, N. Saunders, A.P. Miodownik and J.P. Schillé: Mater. Sci. Eng. A Vols. 413-414 (2005), pp. 465-469.

[31] Z. Guo, N. Saunders, J.P. Schillé and A.P. Miodownik, in: MRS International Materials Research Conference, 9-12 June, 2008, Chongqing, China.

[32]P. Frankel, M. Preuss, A. Steuwer, P.J. Withers and S. Bray: Mater. Sci. Technol. Vol. 25 (2009), pp.640-650.

[33] J. Romero, M.M. Attallah, M. Preuss, M. Karadge and S. Bray: Acta Mater. Vol. 57 (2009), pp. 5582-5592.

[34] W. Li, Ti. Ma and J. Li: Materials \& Design Vol. 31 (2010), pp.1497-1507.

[35]L. Fratini, G. Buffa, D. Campanella and D. La Spisa: Materials \& Design Vol. 40 (2012), pp. 285-291.

[36]J. Sorina-Müller, M. Rettenmayr, D. Schneefeld, O. Roder and W. Fried: Comp. Mater. Sci. Vol. 48 (2010), pp.749-758.

[37]R. Turner, R.M. Ward, R. March and R.C. Reed: Metall. Mater. Trans. B Vol. 43B (2012), pp. 186-197.

[38]F. Schroeder, R.M. Ward, R. Turner, M.M. Attallah, J.C. Gebelin and R.C. Reed, in: Proceedings for the 9th International Trends in Welding Research (2012).

[39] T. Seshacharyulu, S.C. Medeiros, J.T. Morgan, J.C. Malas, W.G. Frazier and Y.V.R.K. Prasad, Mater. Sci. Eng. A Vol. 279 (2000), pp. 290-300.

[40]Z. Guo, N. Saunders, A.P. Miodownik and J.P. Schillé: Int. J. Microstructure and Materials Properties Vol. 4, No. 2 (2009), pp. 187-195.

[41] R.A. Hardin and C. Beckermann, in: Proceedings of the 59th SFSA Technical and Operating Conference, Paper \#3.3, Chicago, 2005, pp. 1-32.

[42]A. Moal and E. Massoni: Eng. Comput. Vol. 12 (1995), pp. 497-512. 